\title{
Imunopatologia induzida por COVID-19: avaliação da resposta imune inata e adaptativa
}

\author{
Letícia Pastorelli Bonjorno ${ }^{1}$, Maria Isabel Fernandes Lopes ${ }^{2}$, \\ Paulo Louzada Junior ${ }^{3}$, Renê Donizeti Ribeiro de Oliveira ${ }^{4}$ \\ DOI: https://doi.org/10.46833/reumatologiasp.2020.19.3.6-11
}

\begin{abstract}
Resumo A doença por coronavírus de 2019 (COVID-19), causada pelo coronavírus 2 da síndrome respiratória aguda grave (SARS-CoV-2), afetou milhões de pessoas em todo o mundo, precipitando um esforço da comunidade científica para compreender sua fisiopatologia. Nosso intuito neste artigo é revisar os aspectos envolvidos nas respostas imunes inata e adaptativa geradas pela infecção reconhecidos até o presente momento, assim como a imunopatologia implicada em pior desfecho, e como, a partir desse conhecimento obtido, novas estratégias terapêuticas podem ser desenvolvidas.
\end{abstract}

Unitermos SARS-CoV-2. COVID-19. Imunidade inata. Citocinas. Fisiopatologia.

\section{INTRODUÇÃO}

A doença por coronavírus de 2019 (COVID-19), causada pelo coronavírus 2 da síndrome respiratória aguda grave (SARS-CoV-2), tornou-se importante problema de saúde em todo o mundo, resultando, até 29 de agosto de 2020, em 24.587 .513 casos confirmados, incluindo 833.556 mortes, relatados à OMS 1 . No Brasil, são 3.846 .153 casos confirmados, com 120.262 mortes$^{2}$. 0 espectro da infecção varia de um curso assintomático a choque séptico ${ }^{3}$. O período de incubação médio é de 5,2 dias ${ }^{4,5}$ e a transmissão ocorre, principalmente, de forma indireta por gotículas oriundas de mucosas das vias aéreas ${ }^{6}$ (Figura 1A). As manifestações clínicas mais frequentes incluem febre, tosse, fadiga, dispneia, dor na orofaringe e cefaleia. Idosos e indivíduos com doenças crônicas (obesidade, hipertensão arterial sistêmica, doença pulmonar obstrutiva crônica, diabete melito e doenças cardiovasculares) constituem o grupo de maior risco para o desenvolvimento de síndrome do desconforto respiratório agudo (SDRA), choque séptico, acidose metabólica e distúrbios da coagulação, e para evoluções fatais. O diagnóstico baseia-se
1. Doutoranda em Medicina pela Universidade de São Paulo. Médica assistente das Disciplinas de Reumatologia e Clínica Médica no Centro Universitário Padre Albino (UNIFIPA), Catanduva-SP, Brasil.

2. Doutoranda em Medicina pela Universidade de São Paulo. Médica assistente das Disciplinas de Reumatologia e Clínica Médica no Centro Universitário Padre Albino (UNIFIPA), Catanduva-SP, Brasil.

3. Doutorado em Medicina pela Universidade de São Paulo (USP) e doutorado Sandwich - Fred Hutchinson Cancer Research Center, Seattle, EUA. Professor titular e chefe do Departamento de Clínica Médica da FMRP-USP, coordenador do Núcleo Apoio a Pesquisa em Doenças Inflamatórias e vice-coordenador de pós-graduação da FMRPUSP. Coordenador adjunto da área Medicina I da CAPES, pesquisador principal e vice-coordenador do CEPID/FAPESP, do Centro de Pesquisa em Doenças Inflamatórias (CRID) e coordenador da disciplina de Reumatologia do HC-FMRP-USP, Ribeirão Preto-SP, Brasil.
4. Pós-doutorado pela Universidade de Glasgow e doutorado em Medicina pela Universidade de São Paulo (USP). Médico assistente da Disciplina de Reumatologia do HCRP-FMRP-USP e do Centro de Reabilitação do HCRP-FMRP-USP, Ribeirão Preto-SP, Brasil.

Correspondência: Dra. Letícia Pastorelli Bonjorno, e-mail: le_bonjorno@hotmail.com.

Como citar este artigo: Bonjorno LP, Lopes MIF, Louzada Junior P, Oliveira RDR. Imunopatologia induzida por COVID-19: avaliação da resposta imune inata e adaptativa. Rev Paul Reumatol. 2020 jul-set;19(3):6-11. DOI: https://doi.org/10.46833/reumatologiasp.2020.19.3.6-11.

Os autores não contaram com apoio financeiro.

Os autores declaram não ter interesses associativos, comerciais, de propriedade ou financeiros que representem conflito de interesse nos produtos e empresas descritos neste artigo. 
na epidemiologia, presença de febre e sintomas respiratórios, exame de imagem dos campos pulmonares (infiltrado em vidro fosco na tomografia computadorizada) e detecção de RNA viral por reação em cadeia de polimerase com transcriptase reversa (RT-PCR) em secreções das vias aéreas ${ }^{3}$. Não há tratamento específico para COVID-19, sendo este de suporte quando os pacientes apresentam pneumonia com necessidade de internação hospitalar. Cada vez mais fica evidente a importância do sistema imune inato na patogênese da doença. Níveis plasmáticos elevados de citocinas inflamatórias e anti-inflamatórias caracterizam a síndrome de liberação de citocinas, também chamada de "tempestade de citocinas”, presente nos pacientes com as formas moderadas a grave da doença. Outro fenômeno cada vez mais reconhecido é a propensão à trombose nestes indivíduos, chamada por alguns de "tormenta trombótica" . Leucocitose, neutrofilia e leucopenia são marcas da forma grave da doença e indicam pior prognóstico ${ }^{8}$. Isso tudo alude a um estado hiperinflamatório decorrente do clearance viral malsucedido contra o SARS-CoV- ${ }^{9}$.

\section{o vírus}

O SARS-CoV-2 é um vírus de RNA de fita simples, envelopado, com diâmetro de 60 a $140 \mathrm{~nm}$, com distintos picos, conferindo aos virions aspecto de coroa solar ${ }^{10}$ (Figura 1B). É reconhecido por receptores de reconhecimento padrão (PPR), tais como os do tipo Toll (Toll like receptors, TLR) 3,7 e 9 nos endossomos, assim como via receptores RIG1 citosólico (RLRs) ${ }^{8}$. Estudos recentes demonstraram a relação entre maior carga viral no diagnóstico e maior mortalidade ${ }^{11}$.

\section{INTERAÇÃO VÍRUS × HOSPEDEIRO}

O SARS-CoV-2 interage com as células alvo por meio da ligação de sua principal glicoproteína de membrana, a proteína $\mathrm{S}$, com proteínas de superfície de membrana celulares epiteliais, como a enzima conversora de angiotensina 2 (angiotensin converting enzyme, ACE2), de forma predominante. A clivagem da proteína $S$ é essencial para a entrada do vírus na célula, o que é amplificado pela serina protease transmembrana TMPRSS2 ${ }^{12}$ (Figura 1C). A ACE2 é expressa na superfície celular em diferentes órgãos, como coração, rim, endotélio, fígado, células intestinais e outros tecidos, dos quais as células alveolares tipo II incluem 83\% do total das células que apresentam este receptor (microestrutura). Ademais, pacientes com fatores de risco cardiovascular e idade avançada podem apresentar expressão elevada da ACE2, implicando maior vulnerabilidade e gravidade da infecção $0^{13}$. A detecção do vírus em locais distantes da via aérea, sem que ocorra viremia, sugere que o vírus possa atingi-los de forma alternativa, como por meio da infecção de neutrófilos, linfócitos e monócitos - fenômeno conhecido como "cavalo de Troia"14.

Em estágios posteriores, quando a replicação viral se acelera, a integridade da barreira endotelial capilar pulmonar é comprometida, ocorrendo infiltrado inflamatório linfomononuclear e de neutrófilos para o microambiente pulmonar, gerando edema alveolar, que radiologicamente se apresenta como as opacidades em vidro fosco típicas dos estudos tomográficos computadorizados. Com a progressão do quadro, ocorre formação de membrana hialina, angioedema pulmonar dependente do sistema calicreína-bradicinina, levando ao aumento da per-

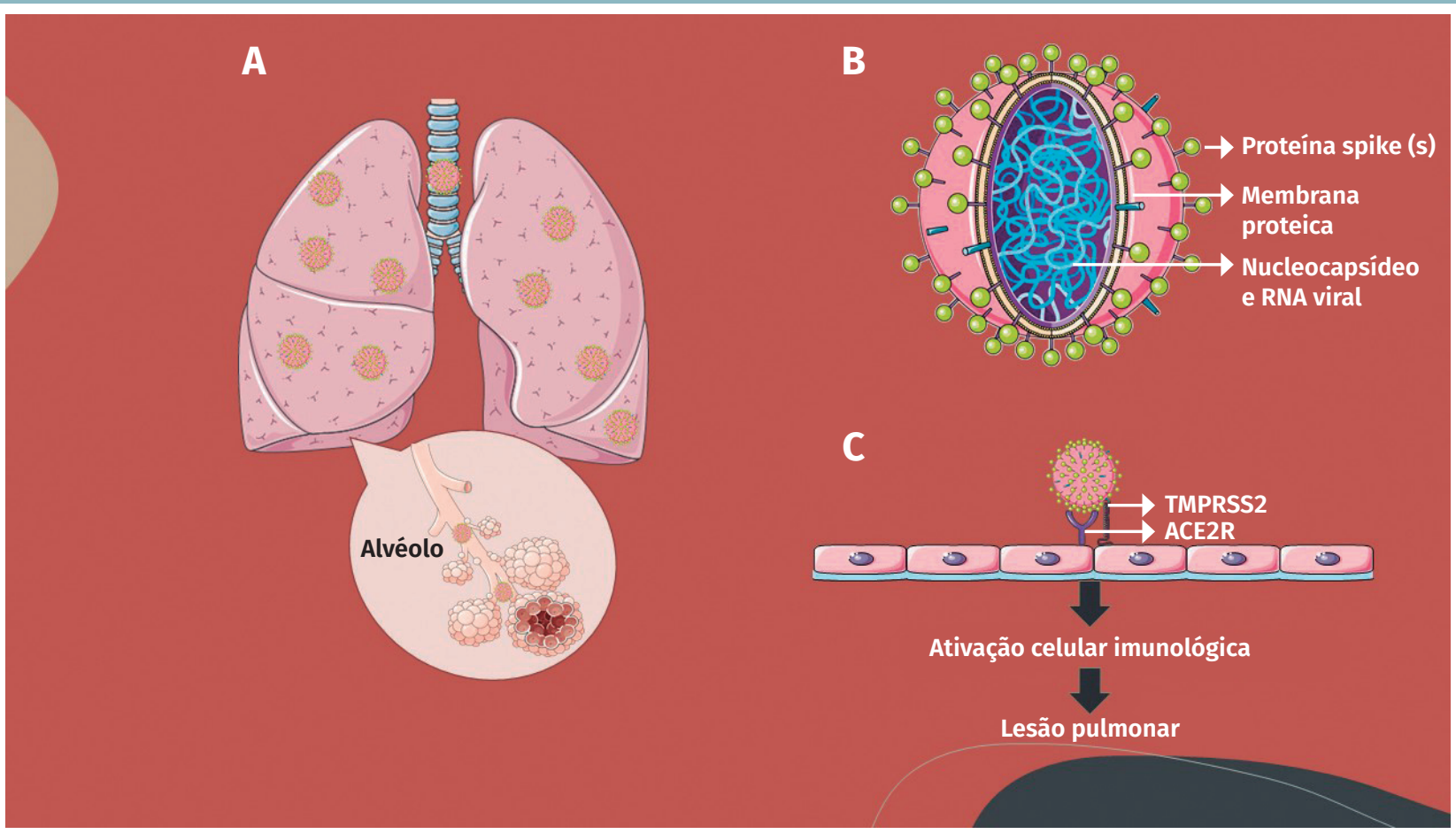

FIGURA 1 A: A transmissão do SARS-CoV-2 ocorre, principalmente, de forma indireta por gotículas oriundas de mucosas das vias aéreas, gerando, em especial, sintomas em vias aéreas superiores e inferiores. B: Desconstruindo o SARS-CoV-2: estrutura viral. C: Interação vírus-células alvo por meio da ligação da proteína S (spike) com ACE2, de forma predominante. A clivagem da proteína S é amplificado pela serina protease transmembrana TMPRSS2. 
meabilidade vascular, culminando em interrupção da barreira endotelial, disfunção da troca gasosa alvéolo-capilar, com prejuízo na capacidade de difusão gasosa, característicos da fase pulmonar da COVID-198,,10.

\section{O SISTEMA IMUNE INATO}

O sistema imune inato tem papel chave na fisiopatologia da COVID-19. Funciona como a primeira linha de defesa antiviral e é essencial para o desenvolvimento da resposta adaptativa. Após a entrada do vírus na célula, ocorre o reconhecimento pelos RLRs e TLRs, precipitando cascatas de sinalização, induzindo fatores de transcrição como fator nuclear kappa B (NF-kB) e fator regulador de interferon (IRF), culminado na transcrição de IFN e citocinas pró-inflamatórias ${ }^{15}$. Como consequência, há elevação de proteína C-reativa, que adquire papel de biomarcador nesta doença, indicando precocemente a possibilidade de progressão da doença para lesão pulmonar, miocardite e desfechos fatais ${ }^{16,17}$.

\section{Síndrome de liberação de citocinas \\ ou "tempestade de citocinas"}

É bem sabido que a evasão do SARS-CoV-2 do sistema imune inato associada à desregulação imune nas fases iniciais da doença são responsáveis pelo fenômeno chamado "tempestade de citocinas”, característica da COVID-19 grave ${ }^{9}$ (Figura 2B). Em resposta ao vírus, o sistema imunológico inato libera citocinas para antagonizá-lo e recrutar respostas imunes adicionais. Entre as citocinas e quimiocinas liberadas, estão: IL-1 $\beta$, proteína quimiotática de monócitos 3 (MCP-3), MIP-1alfa, IL-10, TNF, interferon gama, IL-7, IL-2, G-CSF, sendo a principal delas a IL- $6^{18}$. Na COVID-19, os níveis de IL-6 estão correlacionados com maior gravidade, grau de infiltração pulmonar em pacientes com SDRA, linfopenia e linfo-histiocitose hemofagocítica secundária (LHS) ${ }^{19}$.

Altos níveis de citocinas intensificam o potencial destrutivo gerado pelo vírus, levando à disfunção adicional inflamatória e trombótica. Contribuindo para esse processo, ocorre ativação do sistema complemento, promovendo o acúmulo de neutrófilos e monócitos pró-inflamatórios ${ }^{8}$. Ocorre uma desregulação nos três principais componentes da imunidade inata nas vias aéreas: células dendríticas, macrófagos e células NK, as quais são responsáveis pelo combate à infecção viral até que a imunidade adaptativa esteja envolvida. A liberação tardia de interferon tipo I (IFN) desempenha um papel central na SDRA. Na fase inicial, o SARS-CoV-2 evita os receptores de reconhecimento de padrões (PRRs) e antagoniza a resposta IFN tipo I induzindo vesículas de membrana dupla que não possuem PRRs, capeamento de mRNA e proteínas que inibem as cascatas a jusante do PRR. O IFN tipo I atenuado nas vias aéreas e células epiteliais alveolares ocasiona uma rápida replicação viral. Células dendríticas plasmocitoides (pDCs) e macrófagos são exceções, com uma resposta completa ao SARS-CoV-2, iniciando uma resposta IFN tipo I atrasada, mas robusta, e liberando outras citocinas

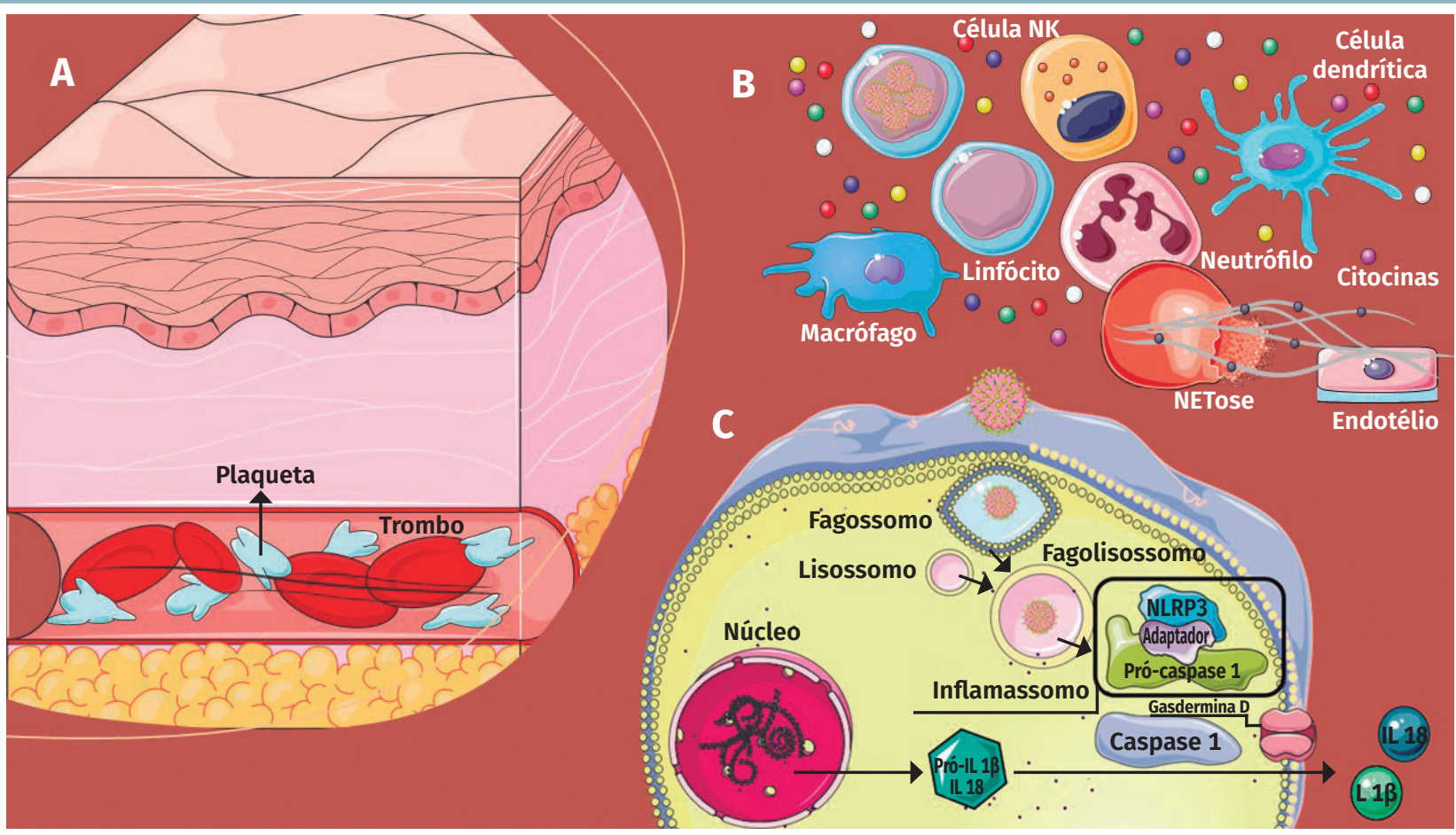

FIGURA 2 Principais aspectos da imunopatologia da COVID-19. A: Coagulopatia nas formas moderadas e graves da doença. B: Representação da "tempestade de citocinas", marco da COVID-19 grave. Em resposta ao vírus, o sistema imunológico inato libera citocinas para antagonizá-lo e recrutar respostas imunes adicionais. Neutrófilos recebem destaque, com ocorrência da NETose. Desregulação nos três principais componentes da imunidade inata nas vias aéreas: células dendríticas, macrófagos e células NK. C: A ativação do inflamassoma e o fenômeno da piroptose parecem estar intrinsecamente relacionados com a COVID-19. 
contra o vírus. Consequentemente, a ativação de cascatas de sinalização do IFN tipo I atraem monócitos-macrófagos inflamatórios (IMMs), neutrófilos, células dendríticas e células NK para o pulmão. Esse processo amplifica a resposta inata, formando um círculo vicioso controlado por citocinas. A resposta imune de células T específicas para vírus é indispensável para eliminá-lo. As células $\mathrm{T}$ reguladoras e as células $\mathrm{T}$ naive regulam negativamente as respostas imunes inatas ativadas por interações célula-célula. Exuberante produção de citocinas, como IFN tipo I, diminui as respostas das células $\mathrm{T}$ ao induzir a sua apoptose, agravando a "tempestade de citocinas" e a linfopenia? .

\section{Participação dos neutrófilos}

Neutrofilia prediz pior prognóstico e a relação neutrófilo/linfócito maior ou igual a 3,3 é um fator de risco independente para a gravidade da doença ${ }^{8}$. As células infectadas pelo SARS-CoV-2 produzem IL-6 e IL-8, que é a principal citocina quimioatraente de neutrófilos ${ }^{20}$. Os neutrófilos ativados recrutados para células endoteliais pulmonares produzem mediadores histiotóxicos, incluindo espécies reativas de oxigênio ${ }^{8}$. Uma particularidade dos neutrófilos é um tipo de morte celular específico chamada NETose $^{21}$. As NETs (armadilhas extracelulares de neutrófilos; do inglês, neutrophil extracellular traps) são originadas por um processo complexo no qual há descondensação da cromatina associada às histonas e desorganização da membrana nuclear, seguida de revestimento do material genético nuclear com moléculas antimicrobianas presentes no citoplasma, sendo a extrusão desse emaranhado de estruturas o resultado final a formar uma espécie de rede capaz de imobilizar microorganismos. Se a NETose ocorrer de forma desregulada ou houver redução do seu clearance, o resultado pode ser o aumento da chance de fenômenos autoimunes, dano tecidual e trombose ${ }^{22}$.

Nosso grupo identificou maior concentração de NETs no plasma e no aspirado traqueal e em material pulmonar de necropsias de pacientes com COVID-19 grave. Além disso, demonstrou que a replicação viral, infecção ativa e estado inflamatório (com liberação de citocinas e quimiocinas) induzem NETose de forma dependente de peptidil arginina deiminase tipo 4 (PAD4), e que as NETs induzem apoptose de células epiteliais pulmonares em cultura. Ademais, demonstrou que o comprimento das NETs é maior nos pacientes com COVID-19 e dependente da carga vi$\mathrm{ral}^{14}$. As NETs induzem os macrófagos a secretar IL1 $\beta$, a qual, em contrapartida, estimula a formação de NETs. Sabe-se também que IL1 $\beta$ induz a produção de IL- $6^{23}$. Portanto, medicamentos que antagonizam a sinalização de IL-6 e/ou IL1ß podem representar estratégias indiretas eficazes para controlar a ativação neutrofílica e reduzir a formação de NETs na COVID-19 grave.

\section{Ativação do inflamassoma e fenômeno da piroptose}

A ativação do inflamassoma e o fenômeno da piroptose parecem estar intrinsecamente relacionados com a COVID -19, o que é visto pelos altos níveis de desidrogenase láctica (DHL), IL-1 e IL-1RA. A ativação do inflamassoma NLRP3 pelo SARS-CoV-2 induz a formação de poros de gasdermina-D na membrana celular, causando secreção de IL-1 $\beta$ e IL-18 para o meio extracelular e influxo de água que levam ao edema e subsequente ruptura celular (piroptose) (Figura 2C). A DHL é uma enzima citosólica que é liberada para o ambiente extracelular após a ruptura da membrana plasmática e seus níveis podem ser usados para monitorizar este fenômeno. Como resultado da ativação do inflamassoma, há aumento dos níveis plasmáticos de IL-1 $\beta$, IL-18 e IL-1RA. Através da piroptose, antígenos e RNA virais poderiam se disseminar na circulação e gerar complexos imunológicos passíveis de deposição em órgãos alvo, como os rins, iniciando cascata inflamatória exuberante ${ }^{24}$. Nosso grupo identificou elevação sérica de produtos derivados do inflamassoma, como caspase 1 ativada e IL-18, nos pacientes com quadros moderados e graves de COVID-19, e que esses produtos foram marcadores de gravidade e pior desfecho clínico ${ }^{25}$.

\section{IMUNIDADE ADAPTATIVA}

Linfócitos T têm papel fundamental nas infecções virais: os linfócitos TCD4+ ativam os linfócitos B para a produção de anticorpos específicos e orquestram a resposta para outras células imunes, enquanto os TCD8+ têm ação citotóxica sobre as células infectadas.

A linfopenia, marcador de pior desfecho para COVID-19, é desencadeada por exaustão funcional de linfócitos TCD4+ e TCD8+, maior expressão de genes envolvidos na apoptose e vias de sinalização p53, impedimento da recirculação de linfócitos T no sangue por retenção nos órgãos linfoides e sítios de infecção ${ }^{8}$. Evidenciamos que monócitos, linfócitos B e T CD4+ são infectados pelo vírus, o que pode também implicar o reduzido número desses tipos celulares nos pacientes com COVID-19 grave. Também descobrimos que o número de monócitos infectados estava relacionado com a progressão temporal da doença, inclusive os monócitos inflamatórios pulmonares $^{26}$. Em resposta à infecção viral, ocorre indução de resposta patogênica Th1 e Th17. Estudos têm observado a redução de linfócitos $\mathrm{T}$ reguladores e linfócitos $\mathrm{T} \gamma \delta$ nos pacientes com COVID-19 grave, os quais possuem funções de resolução de inflamação e proteção antiviral, respectivamente; além de reduzida capacidade de citotoxicidade, e que independente da gravidade, os linfócitos T CD8+ estão mais ativados que linfócitos T CD4+. Durante a recuperação, ao ocorrer a redução dos níveis de IL-6, IL-10 e TNF, advém o aumento das células $\mathrm{T}$ CD $4+$ e $\mathrm{CD} 8+27$.

A resposta humoral é ativada fortemente na infecção pelo SARS-CoV-2, o que pode ser visto pelo rápido aumento de anticorpos específicos produzidos pelos linfócitos B, em torno de 7-14 dias após a infecção. Os principais antígenos virais que desencadeiam a formação de anticorpos são as proteínas S, ORF8 e ORF3b e o nucleocapsídeo. Ainda não é sabido o tempo de meia-vida do linfócito $\mathrm{B}$ de memória gerado, mas os títulos de anticorpos IgG se tornam decrescentes após 8 semanas do início dos sintomas. Mais estudos serão requeridos para determinar 0 grau de proteção a longo prazo ${ }^{28}$. 


\section{“TORMENTA TROMBÓTICA"}

Pacientes com a forma grave da doença apresentam anormalidades da coagulação, o que está associado a um risco aumentado de morte, sendo que os mecanismos associados a esse fenômeno ainda permanecem incertos (Figura 2A). Concomitante ao quadro inflamatório, é sabido que existe um estado pró-trombótico, multifatorial, o qual está relacionado com fatores de risco cardiovascular prévios, imobilização, dano direto do vírus ao endotélio via ACE2, hiperativação de complemento, coagulação intravascular disseminada, microangiopatia trombótica, além de coagulopatia induzida pelo estado inflamatório secundária à “tempestade de citocinas”, NETose e possivelmente síndrome do anticorpo antifosfolípide (SAF) ${ }^{29,30}$.

Relatos de caso têm apresentado coagulopatia, trombocitopenia e presença de anticorpos antifosfolípides, alguns com eventos trombóticos arteriais e venosos nos pacientes com infecção por SARS-CoV-2 ${ }^{29}$. NETs foram vinculadas à iniciação e também ao aumento de eventos trombogênicos em diferentes doenças, diretamente ou através da ativação plaquetária, sendo este evento contribuinte para a formação de microtrombos por meio de interações plaquetas-neutrófilos na SDRA da COVID-1922,31,32. Trombocitopenia e aumento nos níveis de D-dímeros podem funcionar como indícios desta coagulopatia (Figura 3).

\section{O RACIONAL DA TERAPÊUTICA}

A cinética e a intensidade da resposta antiviral são decisivas no resultado do tratamento da COVID-19. Nos casos leves a moderados, a resposta antiviral precoce, principalmente do tipo IFN I, permite a rápida redução da carga viral e evita a depleção de linfócitos T e a hipercitocinemia. Nos casos graves, a resposta antiviral retardada ou reduzida resulta em níveis elevados de citocinas e quimiocinas pulmonares, diminuição das respostas dos linfócitos T específicas para o vírus e deterioração clínica aguda. A intervenção terapêutica precoce nas fases pulmonar e inflamatória parece ser fator determinante para melhora clínica ${ }^{33}$.

A chave para superar a atividade inflamatória excessiva é alcançar um regulador da inflamação enquanto permite que as vias antivirais permaneçam intactas. Até o presente momento, não existe uma vacina eficaz ou tratamento efetivo antiviral, sendo utilizados medicamentos que têm potencial de controlar o processo inflamatório gerado pela infecção viral, como a colchicina $^{34}$ e o corticoide ${ }^{35}$, por exemplo. 0 conhecimento da fisiopatologia desta doença abre caminhos para novos alvos terapêuticos, como inibidores da síntese ou promotores da degradação de NETs ${ }^{14,23}$, inflamassomo ${ }^{24}$, piroptose ${ }^{24}$, citocinas $^{37,38}$, como também anticoagulantes ${ }^{39}$, terapias celulares ${ }^{40}$ e uso de derivados sanguíneos ${ }^{41}$.

\section{CONCLUSÃO}

Inflamação e coagulação são essenciais para a defesa contra patógenos, porém ocorrendo de forma desregulada podem danificar o organismo. Respostas antiviral e inflamatória desencadeadas pelo vírus, assim como o tempo de sua ocorrência, suscitam a importância do tempo nesta doença, inclusive para interferências terapêuticas. 0 entendimento do processo fisiopatológico é essencial para o desenvolvimento de biomarcadores e terapêuticas efetivas.

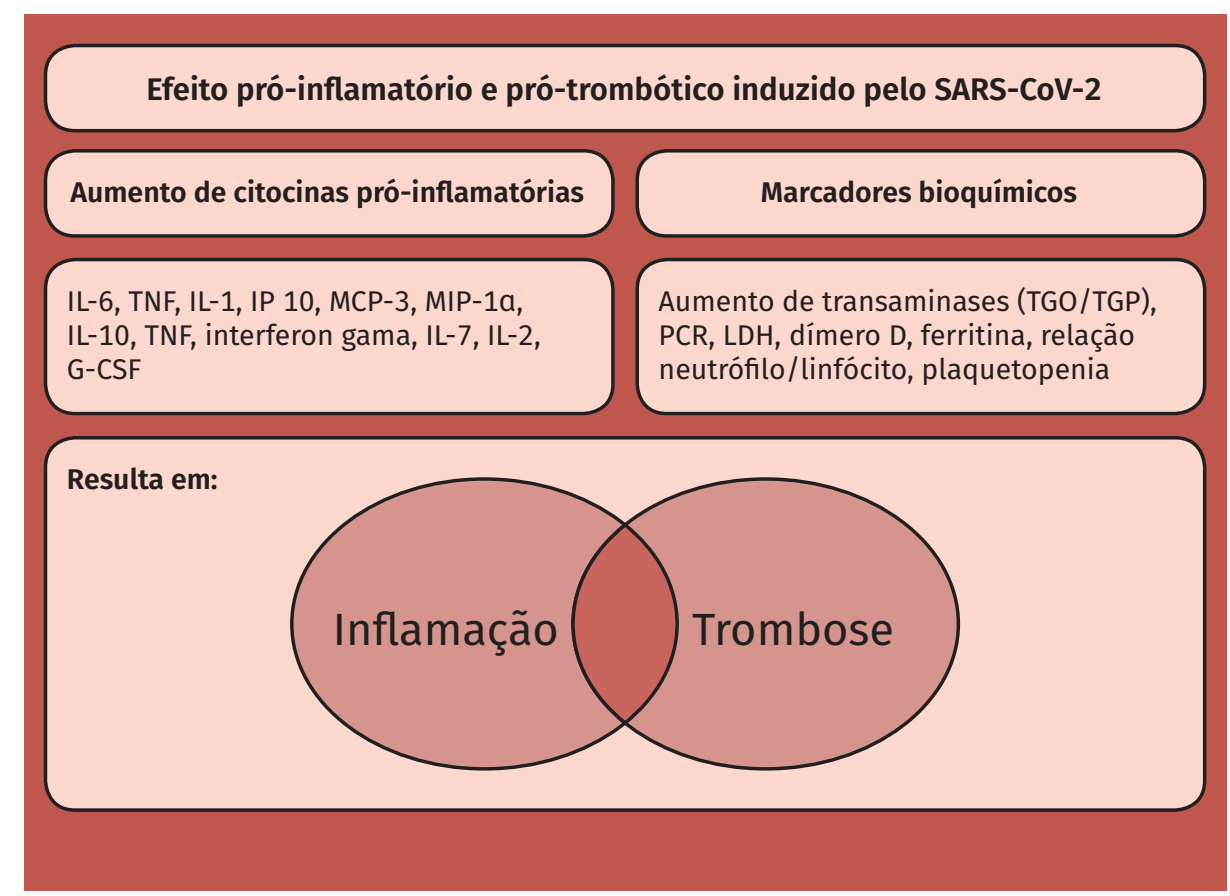

FIGURA 3 Efeito pró-inflamatório e pró-trombótico induzido pelo SARS-CoV-2. 


\section{Referências}

1. World Health Organization. WHO Coronavirus Disease (COVID-19) Dashboard. Disponivel em: https://covid19.who.int.

2. Brasil. Ministério da Saúde. Coronavírus Brasil. Painel de casos de doença pelo coronavírus 2019 (COVID-19) no Brasil pelo Ministério da Saúde. Disponivel em: https://covid.saude.gov.br.

3. Guan W, Ni Z, Hu Y, Liang W, Ou C, He J, et al. Clinical Characteristics of Coronavirus Disease 2019 in China. N Engl J Med. 2020;382:1708-20. https://doi. org/10.1056/NEJMoa2002032.

4. Wu Z, McGoogan JM. Characteristics of and Important Lessons from the Coronavirus Disease 2019 (COVID-19) Outbreak in China: Summary of a Report of 72314 Cases from the Chinese Center for Disease Control and Prevention. JAMA. 2020;323(13):1239-42. https://doi.org/10.1001/jama.2020.2648.

5. Onder G, Rezza G, Brusaferro S. Case-Fatality Rate and Characteristics of Patients Dying in Relation to COVID-19 in Italy. JAMA. 2020;323(18):1775-76. https://doi.org/10.1001/jama.2020.4683.

6. Guo Y, Cao Q, Hong Z, Tan Y, Chen S, Jin H, et al. The origin, transmission and clinical therapies on coronavirus disease 2019 (COVID-19) outbreak - an update on the status. MilitaryMed Res. 2020;7,11. https://doi.org/10.1186/ s40779-020-00240-0.

7. Levi M, Thachil J, Iba T, Levy JH. Coagulation abnormalities and thrombosis in patients with COVID-19. Lancet Haematol. 2020; 7(6):e438-e440. https://doi. org/10.1016/S2352-3026(20)30145-9.

8. Vabret N, Britton GJ, Gruber C, Hedge S, Kim J, Kuksin M, et al. Immunology of COVID-19: current state of the science Immunity. 2020; 52(6):910-41.

9. Zhou G, Chen S, Chen Z. Advances in COVID-19: the virus, the pathogenesis, and evidence-based control and therapeutic strategies. Front Med. 2020;14(2):117-25. https://doi.org/10.1007/s11684-020-0773-x.

10. Wiersinga WJ, Rhodes A, Cheng AC, Peacock SJ, Prescott HC. Pathophysiology, Transmission, Diagnosis, and Treatment of Coronavirus Disease 2019 (COVID-19): A Review. JAMA. 2020;324(8):782-93. https://doi.org/10.1001/ jama.2020.12839.

11. Pujadas E, Chaudh F, McBride R, Richter F, Zhao S, Wajnberg A, et al. SARS-CoV-2 viral load predicts COVID-19 mortality. The Lancet Respiratory Medicine.

12. Luan J, Lu Y, Jin X, Zhang L. Spike protein recognition of mammalian ACE2 predicts the host range and an optimized ACE2 for SARS-CoV-2 infection. BiochemBiophys Res Commun. 2020;526(1):165-9. https://doi.org/10.1016/j. bbrc.2020.03.047.

13. Singh SP, Pritam M, Pandey B, Yadav TP. Microstructure, pathophysiology, and potential therapeutics of COVID-19: A comprehensive review. J Med Virol. 2020;1-25. https://doi.org/10.1002/jmv.26254.

14. Veras FP, Pontelli M, Silva C, Toller-Kawahisa J, Lima M, Nascimento D, et al. SARS-CoV-2 Triggered Neutrophil Extracellular 590 Traps (NETs) Mediate COVID-19 Pathology. medRxiv, 2020. https://doi.org/10.1101/2020.06.08.2 0125823.

15. Gordon DE, Jang GM, Bouhaddou M, Xu J, Obernier K, White KM, et al. A SARS-CoV-2 protein interaction map reveals targets for drug repurposing. Nature. 2020;583(7816):459-68. https://doi.org/10.1038/s41586-020-2286-9.

16. Ji W, Bishnu G, Cai Z, Shen X. Analysis clinical features of COVID-19 infection in secondary epidemic area and report potential biomarkers in evaluation. medRxiv, 2020. https://doi.org/10.21203/rs.3.rs-16658/v1.

17. Xu H, Hou K, Xu H, Li Z, Chen H, Zhang N, et al. Acute Myocardial Injury of Patients with Coronavirus Disease 2019. medRxiv, 2020. https://doi.org/10. $1101 / 2020.03 .05 .20031591$.

18. Mehta P, McAuley DF, Brown M, Sanchez E, Tattersall RS, Manson JJ, et al. COVID-19: consider cytokine storm syndromes and immunosuppression. Lancet. 2020;385(10229):1033-4. https://doi.org/10.1016/S01406736(20)30628-0.

19. Liu T, Zhang J, Yang Y, Ma H, Li Z, Zhang J, et al. The potential role of IL-6 inmonitoring severe case of coronavirus disease 2019. medRxiv, 2020. https:// doi.org/10.1101/2020.03.01.20029769.

20. Li J, Guo M, Tian X, Liu C, Wang X, Yang X, et al. Virus-host interactome and proteomic survey of PMBCs from COVID-19 patients reveal potential virulence factors influencing SARS-CoV-2 pathogenesis bioRxiv, 2020. https://doi. org/10.1101/2020.03.31.019216.

21. Papayannopoulos V. Neutrophil extracellular traps in immunity and disease. Nature Reviews Immunology. 2018;18(2):134-47. https://doi.org/10.1038/ nri.2017.105.
22. Perdomo J, Leung HHL, Ahmadi Z, Yan F, Chong JJH, Passam FH, et al. Neutrophil activation and NETosis are the major drivers of thrombosis in heparin-induced thrombocytopenia. Nat Commun. 2019;10:1322. https://doi. org/10.1038/s41467-019-09160-7.

23. Barnes BJ, Adrover JM, Baxter-Stoltzfus A, Borczuk A, Cools-Lartigue J, Crawford JM, et al. Neutrophil extracellular traps in COVID-19. J. Exp. Med. 2020.

24. Yap JKY, Moriyama M, Iwasaki A. Inflammasomes and Pyroptosis as Therapeutic Targets for COVID-19. J Immunol 2020. https://doi.org/10.4049/jimmunol.2000513.

25. Rodrigues TS, Sa KSG, Ishimoto AY, Becerra A, Oliveira S, Almeida L, et al Inflammasome activation in COVID-19 patients. MedRxiv, 2020. https://doi. org/10.1101/2020.08.05.20168872.

26. Pontelli MC, Castro IA, Martins RB, Veras FP, LaSerra L, Nascimento DC, et al. Infection of human lymphomononuclear cells by SARS-CoV-2.bioRxiv 2020. https://doi.org/10.1101/2020.07.28.225912.

27. Diao B, Wang C, Tan Y, Chen X, Liu Y, Ning L, et al. Reduction and Functional Exhaustion of T Cells in Patients with Coronavirus Disease 2019 (COVID-19). Front. Immunol. 2020. https://doi.org/10.1101/2020.02.18.20024364.

28. Lou B, Li T, Zheng S, Su Y, Li Z, Liu W, et al. Serology characteristics of SARS-CoV-2 infection since the exposure and post symptoms onset. medRxiv, 2020. https://doi.org/10.1101/2020.03.23.20041707.

29. Zhang Y, Xiao M, Zhang S, Xia P, Cao W, Jiang W, et al. Coagulopathy and antiphospholipid antibodies in patients with Covid-19. N Engl J Med. v.382, n. 17, e38, 2010. https://doi.org/10.1056/NEJMc2007575.

30. Gralinsk LE, Sheahan TP, Morrison TE, Menachery VD, Jensen K, Leist SR, et al. Complement activation contributes to Severe Acute Respiratory Syndrome Coronavirus pathogenesis. mBio. v. 9, e01753-18, 2018. https://doi. org/10.1128/mBio.01753-18.

31. Middleton EA, He XY, Denorme F, Campbell RA, Ng D, Salvatore SP, et al. Neutrophil Extracellular Traps (NETs) Contribute to Immunothrombosis in COVID-19 Acute Respiratory Distress Syndrome. Blood. blood.2020007008, 2020. https://doi.org/10.1182/blood.2020007008.

32. Iba T, Levy JH, Connors JM, Warkentin TE, Thachil J, Levi ML. The unique characteristics of COVID-19 coagulopathy. CritCare. 24, 360 (2020). https://doi. org/10.1186/s13054-020-03077-0.

33. Jamilloux $\mathrm{Y}$, Henry T, Belot A, Viel S, Fauter M, El Jammal T, et al. Should we stimulate or suppress immune responses in COVID-19? Cytokine and anti-cytokine interventions. Autoimmun Rev. 2020. https://doi.org/10.1016/j. autrev.2020.102567.

34. Hachim A, Kavian N, Cohen CA, Chin AWH, Chu DKW, Mok CKP, et al. ORF8 and ORF3b antibodies are accurate serological markers of early and late SARS-CoV-2 infection.Nat Immunol (2020). https://doi.org/10.1038/s41590020-0788-0.

35. Lopes MIF, Bonjorno LP, Giannini MC, Amaral NB, Benatti MN, Rezek UC, et al. Beneficial effects of colchicine for moderate to severe COVID-19: an interim analysis of a randomized, double-blinded, placebo controlled clinical trial. MedRxiv, 2020. https://doi.org/10.1101/2020.08.06.20169573.

36. RECOVERY Trial (Randomised Evaluation of COVID-19 Therapy) - Reg. ISRCTN50189673 - Disponivel em: https://www.recoverytrial.net.

37. Tufan A, AvanogluGuler A, Matucci-Cerinic. COVID-19, immune system response, hyperinflammation and repurposing antirheumatic drugs. Turk J MedSci. 2020;50:620-32. https://doi.org/10.3906/sag-2004-168.

38. Liu B, Li M, Zhou Z, Guan X, Xiang Y. Can we use interleukin-6 (IL-6) blockade for coronavirus disease 2019 (COVID-19)-induced cytokine release syndrome (CRS)? J Autoimmun. 2020;11:102452. https://doi.org/10.1016/j. jaut.2020.102452.

39. Mycroft-West C, Su D, Elli S, Li Y, Guimond S, Miller GJ, et al. The 2019 coronavirus (SARS-CoV-2) surface protein (Spike) S1 Receptor Binding Domain undergoes conformational change upon heparin binding. bioRxiv. 2020. https://doi.org/10.1101/2020.02.29.971093.

40. Atluri S, Manchikanti L, Hirsch JA. Expanded Umbilical Cord Mesenchymal Stem Cells (UC-MSCS) as a Therapeutic Strategy in Managing Critically Ill COVID-19 Patients: The Case for Compassionate Use. PainPhysician. 2020;23(2):E71-E83.

41. Bloch EM, Shoham S, Casadevall A, Sachais BS, Shaz B, Winters Jl, et al. Deployment of convalescent plasma for the prevention and treatment of COVID-19. J Clin Invest. 2020;130(6):2757-65. https://doi.org/10.1172/ $\mathrm{JCl} 138745$. 